\title{
Influence of Pre-Match Logical Stimulus for Applying and Developing Strategy to Basketball Team of Faculty of Medicine Universitas Padjadjaran
}

\author{
Razif Fiil Ikhlas, ${ }^{1}$ Vita Muniarti Tarawan, ${ }^{2}$ Vitriana $^{3}$ \\ ${ }^{1}$ Faculty of Medicine, Universitas Padjadjaran, ${ }^{2}$ Departmen of Physiology Faculty of Medicine \\ Universitas Padjadjaran, ${ }^{3}$ Department of Physical Medicine and Rehabilitation Faculty of \\ Medicine, Universitas Padjadjaran/Dr. Hasan Sadikin General Hospital Bandung
}

\begin{abstract}
Background: Logical game is rarely used in sport program as a menu for athletes to prepare their condition in pre-match to improve their cognitive performance. The athletes who have good cognitive performance can think, analyze and solve the problem appeared. Griffith builds a method to improve the athletes' performance by stimulating their cognitive resources. This study aimed to know the influence of pre-match logical stimulus in applying and developing strategy in basketball players.

Methods: The subject of this study was the basketball team players of Faculty of Medicine Universitas Padjadjaran; they were chosen by total sampling based on inclusion and exclusion criteria. Then, they were divided into two groups randomly: control and exposed groups. Both groups will be compared based on the score of each item (in total of 17 items). The assessed items were technique and tactics in the game of basketball. This study was conducted in November 2012 for three weeks. The collected data were analyzed using paired-T test.

Results: Score increased significantly $(\mathrm{p}<0.05)$ in all items for first to third from four times of data retrieval in the exposed group, whereas in the control group, score decreased significantly $(\mathrm{p}<0.05)$ in all items for first to third from four times of data retrieval.

Conclusions: Pre-match logical stimulus can improve the performance, especially technique and tactic in the basketball game. [AMJ.2015;2(3):398-402]
\end{abstract}

Keywords: : Basketball, logical stimulus, strategy

\section{Introduction}

Logic is the study of methods and laws used to distinguish the forms of right reasoning from wrong reasoning. The principle of exercise by using logic in sport was first introduced by Griffith who provides multiple methods of learning that can stimulate students' thought in improving their performance. ${ }^{1}$ Related to the present focus; Kavussanu et al. ${ }^{2}$ conducted a study on the effects of cognitive enhancement to the basketball players through biofeedback methods. The study asked subjects to perform free throw while being given distraction, which was aimed to divert their attention. As the result, they find factors that can affect the player in the successful and unsuccessful free throw as well as feedback to players in anticipation of the factors that make them fail.
In addition, Hong and $\mathrm{O}^{\prime}$ neil ${ }^{3}$ conducted a study by giving questionnaires to subjects to see the effect on performance of cognitive stimulation in motivating based on self-regulation, selfefficacy and effort. As the result, they find that motivated players are able to improve their performance.

This study aimed to know the influence of pre-match logical stimulus in tactical applying and developing for basketball players.

\section{Methods}

This study was a double blinded and analytical research using T-paired test. The subject of this study was the basketball team players of the Faculty of Medicine Universitas Padjadjaran who were chosen by total sampling based on inclusion and exclusion criteria. The inclusion

Correspondence: Razif Fiil Ikhlas, Faculty of Medicine, Universitas Padjadjaran, Jalan Raya Bandung-Sumedang Km.21, Jatinangor, Sumedang, Indonesia, Phone: +62 85294400305 Email: raziffiilikhlas@gmail.com 
Table 1 Average of Personal Item

\begin{tabular}{|c|c|c|c|c|c|c|c|c|}
\hline \multirow{2}{*}{ Item } & \multicolumn{8}{|c|}{ Average } \\
\hline & $\mathrm{K} 1 \overline{\mathrm{X}}_{1}$ & $\mathrm{~K} 2 \overline{\mathrm{X}}_{1}$ & $\mathrm{~K} 1 \overline{\mathrm{X}}_{2}$ & $\mathrm{~K} 2 \overline{\mathrm{X}}_{2}$ & $\mathrm{~K} 1 \overline{\mathrm{X}}_{3}$ & $\mathrm{~K} 2 \overline{\mathrm{X}}_{3}$ & $\mathrm{~K} 1 \overline{\mathrm{X}}_{4}$ & $\mathrm{~K} 2 \overline{\mathrm{X}}_{4}$ \\
\hline Passing & 65.89 & 67.22 & 63.56 & 69.78 & 61.89 & 72.00 & 60.22 & 74.33 \\
\hline Positioning & 67.44 & 66.56 & 65.56 & 69.44 & 63.67 & 71.78 & 62.44 & 73.11 \\
\hline Stealing & 67.11 & 66.56 & 65.67 & 67.89 & 64.44 & 69.89 & 63.56 & 71.11 \\
\hline Blocking & 65.00 & 67.56 & 63.22 & 69.78 & 61.78 & 71.89 & 60.00 & 74.11 \\
\hline Decision & 68.11 & 66.11 & 65.44 & 68.89 & 63.67 & 68.89 & 62.78 & 74.78 \\
\hline Team work & 69.11 & 68.56 & 67.56 & 70.56 & 65.44 & 74.00 & 64.11 & 75.44 \\
\hline Vision & 67.33 & 68.22 & 65.44 & 71.11 & 63.78 & 73.78 & 62.33 & 75.89 \\
\hline Fleeing & 66.33 & 67.11 & 64.89 & 69.89 & 63.11 & 71.56 & 61.00 & 73.67 \\
\hline$\overline{\mathrm{x}}$ total & 67.04 & 67.24 & 65.16 & 69.54 & 63.47 & 71.72 & 62.06 & 74.06 \\
\hline
\end{tabular}

Note: K1= Control Group, K2= Exposed Group, $\overline{\mathbf{X}}_{1=\text { Average score I, }} \overline{\mathbf{X}}_{2=\text { Average score II, }} \overline{\mathbf{X}}_{3=\text { Average Score III }} \overline{\mathbf{X}}_{4=\text { Average }}$ score IV, $\overline{\mathbf{X}}_{\text {total }}=$ Average of total score of all items

criteria were the male players of the basketball team, who have attended basketball practice or have been previously active in a basketball club. Besides, the exclusion criteria were the players who were not students of the fourth grade, and who did not come on the first retrieval, and also who have experienced severe injury, illness, and visual impairment. The subjects were given questionnaires that consisted of questions about their identities, injuries, past experiences in basketball, position, and training. An additional questionnaire was given before retrieval, which consisted of questions about their conditions, problems, and other factors that could affect their performance.
Logical stimulus was given through a questionnaire constructed by the researcher based on literatures and discussions with experts, and comprised four optional questions and answers which allowed players to perform when confronted with certain situations. The data were collected four times where players were judged on 17 items, consisting of eight personal items and nine team items related to the cognitive aspects of basketball games. The assessment of each aspect was based on assessment parameters which consisted of indicators and value for each indicator (+ and -) was compiled by researchers from literatures and discussions

Table 2 Average of Team Item

\begin{tabular}{|c|c|c|c|c|c|c|c|c|}
\hline \multirow{2}{*}{ Item } & \multicolumn{8}{|c|}{ Average } \\
\hline & $\mathrm{K} 1 \overline{\mathrm{X}}_{1}$ & $\mathrm{~K} 2 \overline{\mathrm{x}}_{1}$ & $\mathrm{~K} 1 \overline{\mathrm{X}}_{2}$ & $\mathrm{~K} 2 \overline{\mathrm{x}}_{2}$ & $\mathrm{~K} 1 \overline{\mathrm{x}}_{3}$ & $\mathrm{~K} 2 \overline{\mathrm{x}}_{3}$ & $\mathrm{~K} 1 \overline{\mathrm{x}}_{4}$ & $\mathrm{~K} 2 \overline{\mathrm{x}}_{4}$ \\
\hline Offense & 72 & 69 & 70 & 72 & 68 & 80 & 67 & 84 \\
\hline Defense & 71 & 68 & 68 & 70 & 60 & 72 & 57 & 73 \\
\hline Built up play & 71 & 68 & 69 & 71 & 63 & 75 & 60 & 77 \\
\hline Passing & 66 & 64 & 63 & 68 & 62 & 72 & 61 & 73 \\
\hline Positioning & 68 & 64 & 66 & 68 & 64 & 72 & 63 & 71 \\
\hline Pressing & 69 & 65 & 66 & 70 & 57 & 71 & 55 & 74 \\
\hline Marking & 68 & 65 & 65 & 68 & 56 & 72 & 54 & 74 \\
\hline $\begin{array}{l}\text { Self-efficacy } \\
\text { and regulated }\end{array}$ & 83 & 84 & 83 & 84 & 76 & 85 & 75 & 86 \\
\hline Creativity & 82 & 79 & 81 & 81 & 77 & 82 & 75 & 83 \\
\hline$\overline{\mathbf{X}}_{\text {total }}$ & 72.22 & 69.56 & 70 & 72.44 & 64.78 & 75.67 & 63 & 77.22 \\
\hline
\end{tabular}


Table 3 T-paired Test for Personal Items

\begin{tabular}{|c|c|c|c|c|c|c|c|}
\hline \multirow{2}{*}{ Item } & \multirow{2}{*}{ Team } & \multicolumn{2}{|c|}{$\bar{x}_{1} / \bar{x}_{2}$} & \multicolumn{2}{|c|}{$\bar{x}_{2} / \bar{x}_{3}$} & \multicolumn{2}{|c|}{$\bar{x}_{3} / \bar{x}_{4}$} \\
\hline & & $\mathbf{t}$ & p & $\mathbf{t}$ & p & $\mathbf{t}$ & p \\
\hline \multirow[t]{2}{*}{ Passing } & $\mathrm{K} 1$ & 4.950 & $0.001^{* *}$ & 4.472 & $0.002^{* *}$ & 5.000 & $0.001^{* *}$ \\
\hline & K2 & -4.914 & $0.001^{* *}$ & -6.261 & $0.000^{* *}$ & -2.066 & 0.073 \\
\hline \multirow[t]{2}{*}{ Positioning } & K1 & 9.430 & $0.000^{* *}$ & 4.857 & $0.001^{* *}$ & 3.773 & $0.005^{* *}$ \\
\hline & K2 & -4.914 & $0.001^{* *}$ & -6.261 & $0.000^{* *}$ & -2.066 & 0.073 \\
\hline \multirow[t]{2}{*}{ Decision } & K1 & 6.532 & $0.000^{* *}$ & 3.600 & $0.007^{* *}$ & 1.512 & 0.169 \\
\hline & K2 & -6.402 & $0.000^{* *}$ & -4.996 & $0.001^{* *}$ & -3.546 & $0.008^{* *}$ \\
\hline \multirow[t]{2}{*}{ Team work } & K1 & 3.092 & $0.015^{*}$ & 5.429 & $0.001^{* *}$ & 2.309 & 0.050 \\
\hline & K2 & -6.000 & $0.000^{* *}$ & -6.847 & $0.000^{* *}$ & -2.726 & $0.026^{*}$ \\
\hline \multirow[t]{2}{*}{ Vision } & K1 & 4.857 & $0.001^{* *}$ & 4.472 & $0.002^{* *}$ & 3.250 & $0.012^{*}$ \\
\hline & K2 & -3.043 & $0.016^{*}$ & -6.532 & $0.000^{* *}$ & -3.033 & $0.016^{*}$ \\
\hline \multirow[t]{2}{*}{ Stealing } & K1 & 5.965 & $0.000^{* *}$ & 3.773 & $0.005^{* *}$ & 2.286 & 0.052 \\
\hline & K2 & -4.619 & $0.002^{* *}$ & -4.243 & $0.003^{* *}$ & -2.817 & $0.023 *$ \\
\hline \multirow[t]{2}{*}{ Blocking } & K1 & 4.097 & $0.003^{* *}$ & 4.274 & $0.003^{* *}$ & 5.488 & $0.001^{* *}$ \\
\hline & K2 & -4.061 & $0.004^{* *}$ & -4.642 & $0.002^{* *}$ & -4.264 & $0.003^{* *}$ \\
\hline \multirow[t]{2}{*}{ Fleeing } & K1 & 2.490 & $0.038^{*}$ & 4.880 & $0.001^{* *}$ & 2.873 & $0.021^{*}$ \\
\hline & $\mathrm{K} 2$ & -6.934 & $0.000^{* *}$ & -3.780 & $0.005^{* *}$ & -6.008 & $0.000^{* *}$ \\
\hline
\end{tabular}

Note: $\mathrm{K} 1=$ Control Group, $\mathrm{K} 2=$ Exposed Group, $\overline{\mathbf{X}}_{1=\text { Average score I, }} \overline{\mathbf{X}}_{2=\text { Average score II, }} \overline{\mathbf{X}}_{3=\text { Average Score III }} \overline{\mathbf{X}}_{4=\text { Average }}$ score IV, * $=p<0.05, * *=p<0.01$

with experts; the assessment was performed by the assessors every two minutes. This research was conducted in November 2012 for three weeks.

\section{Results}

The subject consisted of 24 players: 11 for the exposed group and 13 for the control group. When conducting the retrieval process, two subjects in the exposed group and one subject in the control group were not present; therefore, the data were incomplete. In the processing of statistics, the numbers of both groups were equated with random selection of the control group.

Table 1 and 2 show a reduction of average in the control group score in all items, meanwhile, in the exposed group all of the scores were improving.

Table 3 shows the personal score of the control group reduced indicating significantly $(\mathrm{p}<0.05)$, except for decision and stealing in the third and fourth data did not reduced significantly (0.169 and 0.052). In addition, the personal score for exposed group has increased significantly $(\mathrm{p}<0.05)$, except for both positioning and teamwork in the third and fourth data did not have significant reduction (0.073 and 0.05 ).

Table 4 shows the exposed group significantly experienced improvement in all team items in comparison with the control group $(\mathrm{t}=-4.837$ and $\mathrm{p}=0.00)$.

\section{Discussion}

The statistics test showed that giving stimulus through logic game before a match could increase and develop the strategy of a basketball game significantly. This was found on an average of 17 out of 8 aspects of personal

Table 4 T-paired Test for Team Items

\begin{tabular}{ccccc}
\hline & $\overline{\mathbf{x}} \mathbf{1}_{\mathbf{t}}-\overline{\mathbf{x}} \mathbf{2}_{\mathbf{t}}$ & sd & $\mathbf{t}$ & sig (2 tailed) \\
\hline Team 1/Team 2 & -5.889 & 7.305 & -4.837 & $0.000^{* *}$ \\
\hline
\end{tabular}

Note: $\overline{\mathrm{X}} 1_{\mathrm{t}}=$ average of total score of control group, $\overline{\mathrm{X}} 2_{\mathrm{t}}=$ average of total score of exposed group, ${ }^{* *}=\mathrm{p}<0.01$ 
Razif Fiil Ikhlas, Vita Muniarti Tarawan, Vitriana: Influence of Pre-Match Logical Stimulus for Applying and 401 Developing Strategy to Basketball Team of Faculty of Medicine Universitas Padjadjaran

assessment and 9 aspects of team assessment.

The average of the exposed group was higher than the control group. The T-paired test showed that the score for the treatment group was significantly higher with $\mathrm{p}<0.05$. This supports the previous theories stating that giving cognitive stimulus could increase the athletes' performance. There was an insignificant increase in the positioning aspect, $\mathrm{p}=0.073$, however, this aspect increased significantly at the previous scoring. This is assumed based on the research conducted by Marois and Ivanoff ${ }^{4}$, revealing that the players given logic stimulus could reach cognitive threshold towards the aspect stimulated, and then an insignificant increase would occur. This threshold is influenced by some factors affecting their cognitive processes such as cognitive resource, potential cognitive, attention, memory, cognitive inhibition, and executive function. ${ }^{5}$

The cognitive resource influences the speed and its capacity in processing and storing the information received, and makes it as an experience which will be a base for the following problem. ${ }^{6}$ While attention is a process to identify the received information at the time of being able to catch the meaning of that information, whether it is simple or complex information. ${ }^{5}$ This factor helps an individual to pay attention at simple and implicit things in order to catch the whole meaning of the information given. ${ }^{7}$ In addition, potential cognitive has the function to solve problems quickly and to be responsive. It is due to the fact that this factor identifies the quality of individual cognitive function to recall all background experiences from the previous knowledge and theories. ${ }^{8}$ Furthermore, cognitive inhibition is a factor that organizes the affectivity and flexibility of the function of human brain by controlling all attention processes, reducing the disturbance thoughts, controlling motorist actions, and helping in changing and choosing important thoughts. ${ }^{9}$ Moreover, the executive function plays a role in taking decision and thinking critically and creatively. ${ }^{10,11}$

There is another assumption of the result. Five out of 9 players in the exposed group wrote in their questionnaire during the fourth data collection that they were tired, so they did not actively take position during the game. This was also supported by the note on the evaluation sheet stating that 4 out of 9 players were not active during the game. While the decreasing of the control group was assumed that they were under pressure because there was an increase of performance of the treatment group. Glaze ${ }^{12}$ confirmed this by stating the causes such as the failure in formulating team's play, loss of focus towards the purpose, unability to use the available resources, failure to maximize the ability and activities, loss of intrinsic motivation and failure to perform well. Another assumption is that the players would have difficulty in performing maximally due to a difficult situation that they hardly solved even though they have tried by using their ability. The ability to solve the problem needs more responses which need to be trained..$^{13,14}$

There were two limitations of this study. The first was the limitation for developing the questionnaire toward the other items related to the cognitive function for basketball game. The second was the limitation for developing the assessment parameters for each item in this study. More indicators for parameter and value categories were needed for item scoring.

After four times data collection, it was found that the average of the treatment group has increased compared to the control group. Also, a significant increase was found in all evaluation aspects from the first until the third retrieval of data collection.

\section{References}

1. Green CD. Coleman Roberts Griffith. In: Dewsburry DA, Wertheirmer M, editors. Portraits of pioneers in psychology. New York: Routledge; 2006.

2. Kavussanu M, Crews DJ, Gill DL. The effects of single versus multiple measures of biofeedback on basketball free throw shooting performance. IJSP. 1998;29(2):132-44.

3. Hong E, O'Neil HF. Construct validation of a trait self-regulation model. Int J Psychol. 2001;36:186-94.

4. Marois R, Ivanoff J. Capacity limits of information processing in the brain. Trends Coqn Sci. 2005;9(6):296-305.

5. Santrock WJ. Adolescence. 12th ed. New York: McGraw-Hill; 2008

6. Kail R. Speed of information processing: developmental change and links to intelligence. J Sch Psychol. 2000;38(1):5161.

7. Klimkeit EI, Mattingley JB, Sheppard DM, Farrow M, Bradshaw JL. Examining the development of attention and executive functions in children with a novel paradigm. Child Neuropsychol. 2004;10(3):201-11.

8. Labouvie-Gief G. Emerging structures 
of adult thought. In: Arnet JJ, Tanner JL, editors. Emerging adults in America. Washington DC: APA books; 2006.

9. Anderson VA, Anderson P, Northan E, Jacobs R, Catroppa C. Development of executive functions through late childhood and adolescence in an Australian sample. Dev Neuropsychol. 2001;20(1):385-406.

10. Klaczynski PA, Byrnes JP, Jacobs JE. Introduction to the special issue: the development of decision making. J Appl Dev Psychol. 2001;22(3):225-36.

11. Reyna VF, Estrada SM, DeMarinis JA, Myers RM, Stanisz, Mills BA. Neurobiological and memory models of risky decision making in adolescents versus young adults. J Exp Psychol Learn Mem Cogn. 2011;37(5):1125-42.
12. Gaze S. Team development and the five traits of great teams. 2011. [Cited 2012 August 12]. Available at: http:// greatresultsteambuilding.net/traits-greatteams/.

13. Scott WD, Beevers CG, Mermelstein RJ. Depression vulnerable and non-vulnerable smokers after a failure experience: examining cognitive self-regulation and motivation. Behav Modif. 2008;32(4):51939.

14. Kuhn D, Katz J, Dean D. Developing reason. Thinking \& Reasoning. 2004;10(2):19721. 